\title{
APLICAÇÃO DE GPR E CINTILOMETRIA PARA A CARACTERIZAÇÃO DE DESCONTINUIDADES ESTRUTURAIS E LITOLÓGICAS NA PORÇÃO LESTE DA SERRA DO CANTAGALO, SÃO TOMÉ DAS LETRAS (MG)
}

\author{
Juni Silveira Cordeiro으, Ana Flávia Ferreira², Paulo Roberto Antunes Aranha ${ }^{3}$, \\ Ricardo Diniz da Costa ${ }^{4} \&$ Jadir Alves da Silva Filho ${ }^{5}$
}

\begin{abstract}
RESUMO
A aplicação de métodos geofísicos na caracterização de descontinuidades estruturais e litológicas em subsuperfície mostrou-se de grande importância no auxílio do mapeamento geológico em escala de semi-detalhe realizado na porção sul da Quadrícula São Tomé das Letras - Minas Gerais. Foram utilizados, de maneira simultânea, os métodos de Georadar e cintilometria que sobrepostos resultaram em 6 radargramas e 5 gráficos de cintilações por segundo (cps). Os perfis foram realizados a leste da Serra do Cantagalo, abrangendo a Unidade Córrego Caí, sendo que o primeiro perfil compreende o contato desta unidade com as seqüências A e B pertencentes à Unidade Serra do Cantagalo. Características marcantes nos radargramas obtidos são: (1) a presença de um padrão de reflexão contínuo, com inclinação para os quadrantes $\mathrm{W}$, condizente com os planos de foliações encontrados em quartzitos, xistos e gnaisses da região e (2) um segundo padrão de reflexão, com inclinação maior do que a topografia do terreno e oblíquo aos refletores associados aos planos de foliação, correlacionado à família de fraturas perpendiculares à direção das serras de São Tomé e Cantagalo. As variações bruscas nos valores de cps nos gráficos de cintilometria corroboram os perfis de Georadar, marcando, principalmente, possíveis contatos litológicos. Dificuldades quanto à aplicação das técnicas geofísicas surgem, principalmente, quando da aplicação do Georadar em material com características elétricas condutoras e em locais com presença de ruídos eletromagnéticos.
\end{abstract}

Palavras-chave: georadar, cintilometria, mapeamento geológico

\section{INTRODUÇÃO, LOCALIZAÇÃO GEOGRÁFICA E ACESSO}

Este trabalho apresenta os resultados obtidos com a aplicação dos métodos geofísicos de Georadar (GPR) e cintilometria na escarpa leste da Serra do Cantagalo, porção sul da Quadrícula São Tomé das Letras (MG).

O objetivo principal desta investigação foi verificar a existência de descontinuidades/contatos litológicos ocorrentes na região em questão, testando, desta forma, a aplicação destes métodos no auxílio ao mapeamento geológico de detalhe.

O município de São Tomé das Letras, localizado na porção sul do estado de Minas Gerais (Figura 1), dista cerca de $340 \mathrm{~km}$ de Belo Horizonte. O acesso à área pode ser realizado a partir de Belo Horizonte pela Rodovia BR-381 (Fernão Dias) em direção ao trevo de Três Corações, a partir do qual segue-se pela MG-868 por cerca de $56 \mathrm{~km}$, até a sede municipal de São Tomé das Letras. Um acesso alternativo passa pela estrada não pavimentada, próximo ao Posto Novo Rio I (Carmo da Cachoeira) via São Bento do Abade.

\section{CONTEXTO GEOLÓGICO REGIONAL}

Na porção sul da Quadrícula São Tomé das Letras podem ser observadas onze unidades litológicas (Cordeiro \& Ferreira 2005 - Figura 2), divididas nos domínios autóctone (correlato à unidade arqueana ou paleoproterozóica de Trouw et al. 2003) e alóctone (correlatas às associações litológicas $\mathrm{Na}_{1+2}, \mathrm{Na}_{3} \mathrm{e} \mathrm{Na}_{4}$ da Megasseqüência Andrelândia propostas por Trouw et al. 2003).

O domínio considerado autóctone, denominado informalmente Unidade Córrego Caí por Cordeiro \& Ferreira (2005), é representado por gnaisse, talco xisto, quartzo-sillimanita xisto, quartzito, metagranitóide, hematita magnetitito, anfibolito, andaluzita xisto e clorita xisto.

O domínio alóctone, constituído por rochas metassedimentares, é subdividido em seis unidades, denominadas informalmente (Cordeiro \& Ferreira 2005), Unidade Serra do Cantagalo (subdivida nas seqüências $\mathrm{A}$, composta por gnaisse - correlata à unidade $\mathrm{Na}_{1+2}$ de Trouw et al. 2003; B, composta por intercalações de quartzito e moscovita xisto - correlata à unidade $\mathrm{Na}_{4}$ de Trouw et al. op.cit. e $\mathrm{C}$, composta por quartzito - correlata à unidade $\mathrm{Na}_{3}$ de Trouw et al. 2003); Unidade Córrego da Marcelina, constituída por cordierita gnaisse e correlata à unidade $\mathrm{Na}_{1+2}$ de Trouw et al. (op.cit.); Unidade Córrego da Vargem Grande, formada por quartzito, gnaisse e xistos - também

1 - Mestranda em Geologia Regional CPMTC-IGC-UFMG. E-mail: junicordeiro@gmail.com;

2 - Graduada em Geologia pela UFMG - Grupo Votorantim Metais, Vazante, MG. E-mail: ana.ferreira@vmetais.com.br; 3 - IGC-UFMG. E-mail: aranha@geol.igc.ufmg.br;

4 - CPMTC-IGC-UFMG. E-mail: biduufmg@gmail.com; 5 - Graduando em Engenharia de Minas - UFMG 


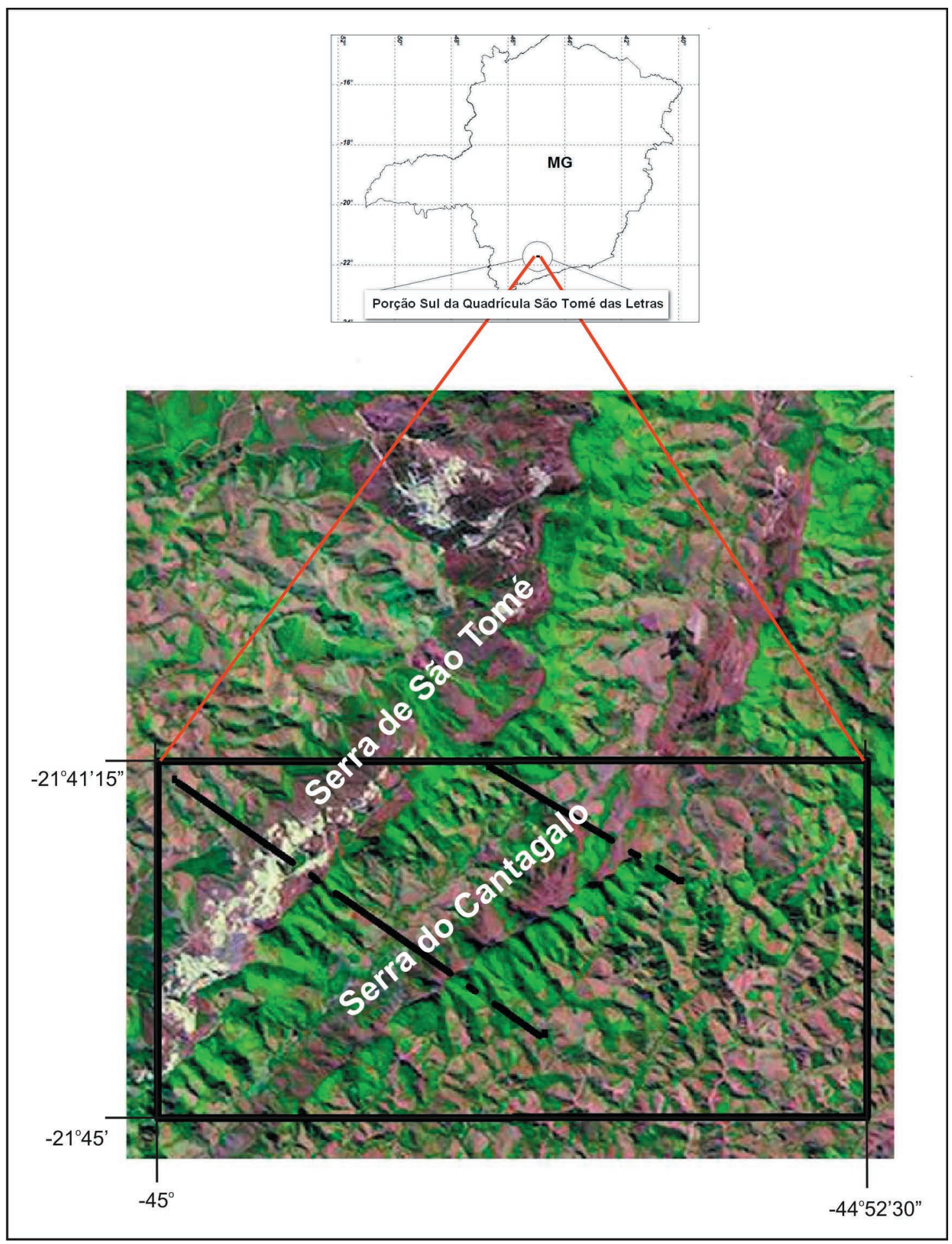

Figura 1: Mapa de localização da porção sul da Quadrícula São Tomé das Letras (Cordeiro \& Ferreira 2005).

correlata à unidade $\mathrm{Na}_{1+2}$ de Trouw et al. (2003); Unidade Serra de São Tomé (subdivida nas seqüências D, E e F; compostas, respectivamente, por anfibóliobiotita gnaisse - correlata à unidade $\mathrm{Na}_{1+2}$ de Trouw et al. (op.cit.), intercalações de quartzito e moscovita xisto e quartzito - ambas correlatas à unidade $\mathrm{Na}_{3}$ de Trouw et al. 2003), Unidade Córrego da Cachoeira, formada por quartzito e xisto - correlata à unidade $\mathrm{Na}_{4}$ de Trouw et al. (2003) e Unidade Ribeirão do Engenho, constituída por biotita xisto, correlata à unidade $\mathrm{Na}_{1+2}$ de Trouw et al. (op.cit).
Os planos de foliação medidos (Cordeiro \& Ferreira 2005) apresentam o mesmo padrão em diferentes litotipos, com direção preferencial $\mathrm{N} 30^{\circ} \mathrm{E} /$ $15^{\circ} \mathrm{NW}$. Uma lineação mineral de estiramento, representada, principalmente, por sericita, apresenta-se freqüentemente oblíqua aos planos de foliação (com maior densidade de medidas em $\mathrm{N} 42^{\circ} \mathrm{E}$ com caimento suave para $\mathrm{SW}$ ), sendo caracterizada por uma grande dispersão (cerca de $90^{\circ}$ ) das atitudes medidas.

A existência de clivagem de crenulação e de uma guirlanda de pontos polares dos planos de foliação 
sugere a existência de três planos de foliação $\left(\mathrm{S}_{\mathrm{n}}, \mathrm{S}_{\mathrm{n}+1} \mathrm{e}\right.$ $\mathrm{S}_{\mathrm{n}+2}$ ), como já apresentado por Trouw et al. (1980, 1983, 2003). Estruturas sedimentares não foram encontradas na área, mas diversos trabalhos publicados, envolvendo tanto a área de mapeamento como regiões próximas a esta, interpretam a foliação $S_{n}$ como sendo paralela à superfície $\mathrm{S}_{0}$.

A análise das estruturas rúpteis realizada por Cordeiro \& Ferreira (2005) indica um controle geomorfológico das serras de São Tomé e Cantagalo frente ao padrão de fraturamento, o qual corresponde, em sua maioria, a fraturas de desconfinamento com um máximo principal em $\mathrm{N} 43^{\circ} \mathrm{E} / 72^{\circ} \mathrm{SE}$ (correspondendo a aproximadamente $6 \%$ das fraturas investigadas, direção esta paralela à direção das serras) e sub-máximos em $\mathrm{N} 45^{\circ} \mathrm{W} /$ sub-vertical (direção perpendicular à direção das serras), $\mathrm{N} 16^{\circ} \mathrm{W} /$ sub-vertical e $\mathrm{N} 72^{\circ} \mathrm{W} / 76^{\circ} \mathrm{NE}$, sendo que estas últimas direções representam, possivelmente, um par conjugado de fraturas.

\section{LEVANTAMENTO E PROCESSAMENTO DE DADOS GEORADAR E CINTILOMETRIA}

GPR - O método GPR tem sido aplicado em Minas Gerais no estudo de coberturas superficiais na região de Gouveia (e.g. Neves et al. 1997; Aranha et al. 1998; Horn et al. 1998; Aranha 2003) e na identificação de diques nas proximidades de Diamantina (Aranha \& Horn 2000).

A campanha geofísica realizou-se através de seis perfis de Georadar nos quais utilizou-se o aparelho RAMAC, do Mala GeoScience. Nesta pesquisa foram utilizadas antenas de baixa freqüência $(50$ e $100 \mathrm{MHz})$ com o intuito de se investigar regiões mais profundas (dezenas de metros).

O levantamento foi executado com antenas a distância constante (common offset), no qual o sistema é transportado ao longo de uma direção obtendo-se um perfil das reflexões versus posição. Foi utilizado o modo de 16 stacks (pulsos rápidos) com o objetivo de aumentar a relação sinal/ ruído da onda emitida, melhorando a qualidade dos dados adquiridos no campo. Os perfis foram planejados de modo que cortassem perpendicularmente a direção dos contatos de interesse.

Os demais parâmetros utilizados para a elaboração dos perfis foram: freqüencia de amostragem aproximadamente 10 vezes a freqüência central da antena utilizada; janela de tempo de 400ns; a freqüência central utilizada foi de $100 \mathrm{MHz}$ (em todos os cinco perfis) e de $50 \mathrm{MHz}$ no perfil coincidente com o de $100 \mathrm{MHz}$, realizado na escarpa leste da Serra do Cantagalo. O espaçamento entre os pontos de aquisição de dados foi de $25 \mathrm{~cm}$ para a antena de $100 \mathrm{MHz}$ e de $50 \mathrm{~cm}$ para a antena de $50 \mathrm{MHz}$.

O processamento de dados objetivou melhorar a qualidade dos resultados obtidos no campo, para que a interpretação das imagens apresentasse uma melhor precisão e maior correspondência com a realidade. A edição compreendeu a organização dos dados, a correção destes, o posicionamento das linhas etc. Manipulações fundamentais foram aplicadas aos dados tais como declipping, filtragem, marcação do "tempo zero", ganhos temporais e correção topográfica (Aranha 2003).

CINTILOMETRIA - O método geofísico da cintilometria fundamenta-se na captura de radiação proveniente de elementos radioativos naturais $\left({ }^{40} \mathrm{~K},{ }^{232} \mathrm{Th}\right.$ e $\left.{ }^{223} \mathrm{U}\right)$ encontrados em minerais, intimamente correlacionados à composição mineralógica das rochas. Em particular, desempenham um papel predominante no estudo da radioatividade das rochas da crosta terrestre, devido à abundância inicial destes elementos.

Nesta pesquisa se buscava caracterizar o contato entre diferentes litotipos em função da marcação da radioatividade dos mesmos e não o valor exato da emanação radioativa de cada um, assim sendo, não foram realizadas medidas de radiação de background.

Para marcar o ponto de aquisição foi utilizado um par de GPS no modo diferencial, já para o levantamento dos dados cintilométricos fez-se uso do cintilômetro de modelo SC-132, da Mount Sopris Instrument Co. O procedimento para a obtenção desses dados teve começo com a permanência de um GPS, estático, por cerca de 14 minutos antes de se iniciar a marcação dos pontos, visando uma melhor estabilização dos satélites. O cintilômetro foi colocado na superfície do terreno para a realização das medições de CPS, enquanto também se media com o GPS, decorridos 40 segundos e com espaçamento de cerca de $1 \mathrm{~m}$, a posição do ponto de amostragem.

Os dados de GPS recolhidos no campo, necessários em ambos os métodos geofísicos, foram corrigidos tomando-se como base a estação total de Varginha (VARG), de código internacional 91930, administrada pela CEMIG, com a utilização de software que grava, processa e exporta os dados de GPS. O equipamento usado em campo para a coleta das posições foi Ashtech Solutions $^{T M}$ assim como o programa aplicado para a correção dos dados.

Após estas correções, as coordenadas foram transformadas em coordenadas planares para a construção de gráficos de distância (em metros) x cintilações por segundo (cps), para a elaboração dos perfis de cintilometria.

\section{RESULTADOS}

Foram realizados, de maneira simultânea, 6 perfis de GPR (sendo que dois perfis foram realizados na escarpa leste da Serra do Cantagalo (Figura 3), sobrepostos, utilizando-se antenas com freqüência de 50 e 100MHZ e abrangendo os contatos entre as seqüências A e $\mathrm{B}$ pertencentes à Unidade Serra do Cantagalo e os demais na Unidade Córrego do Caí) e cinco perfis de cintilometria, obtidos ao longo dos perfis de GPR. 


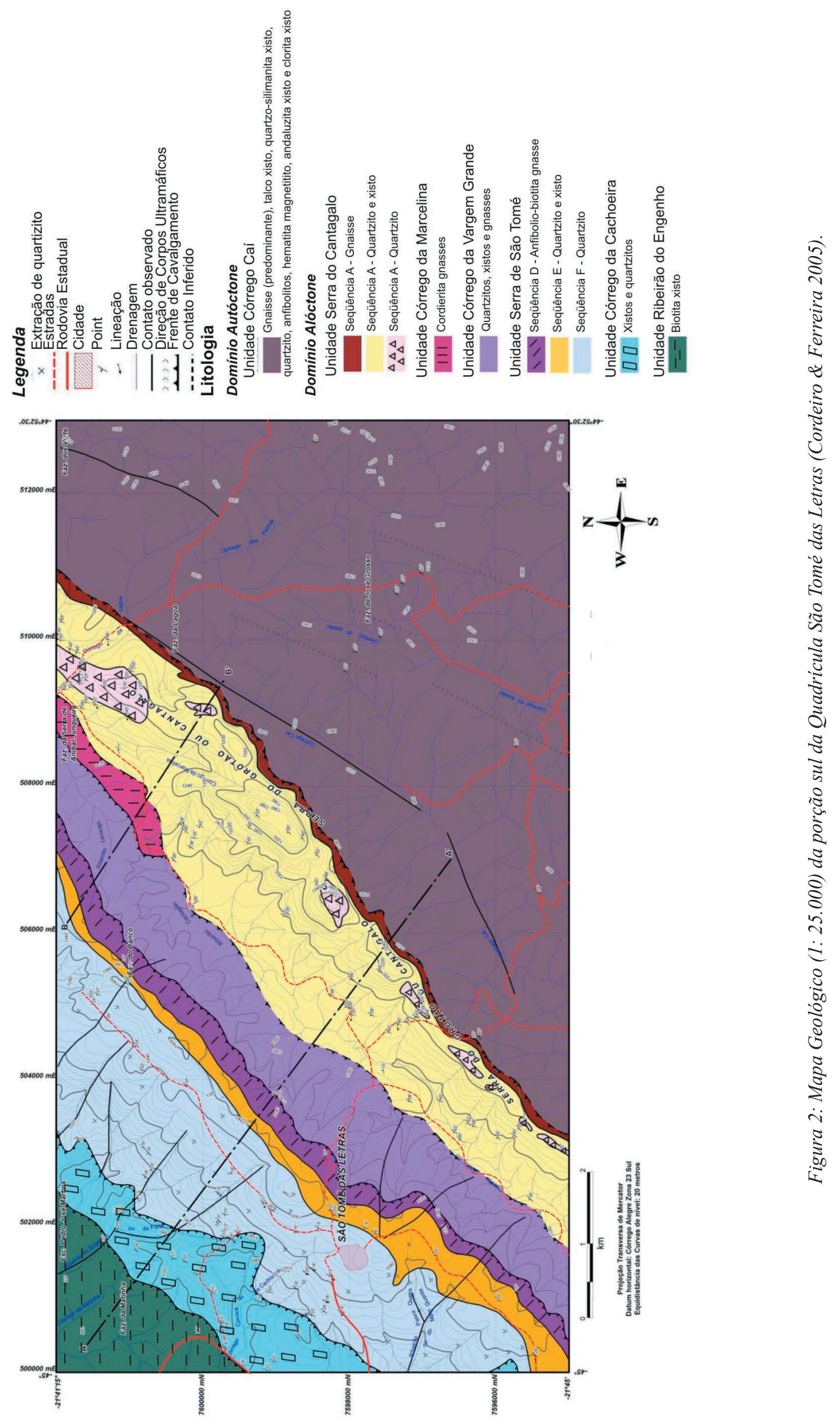




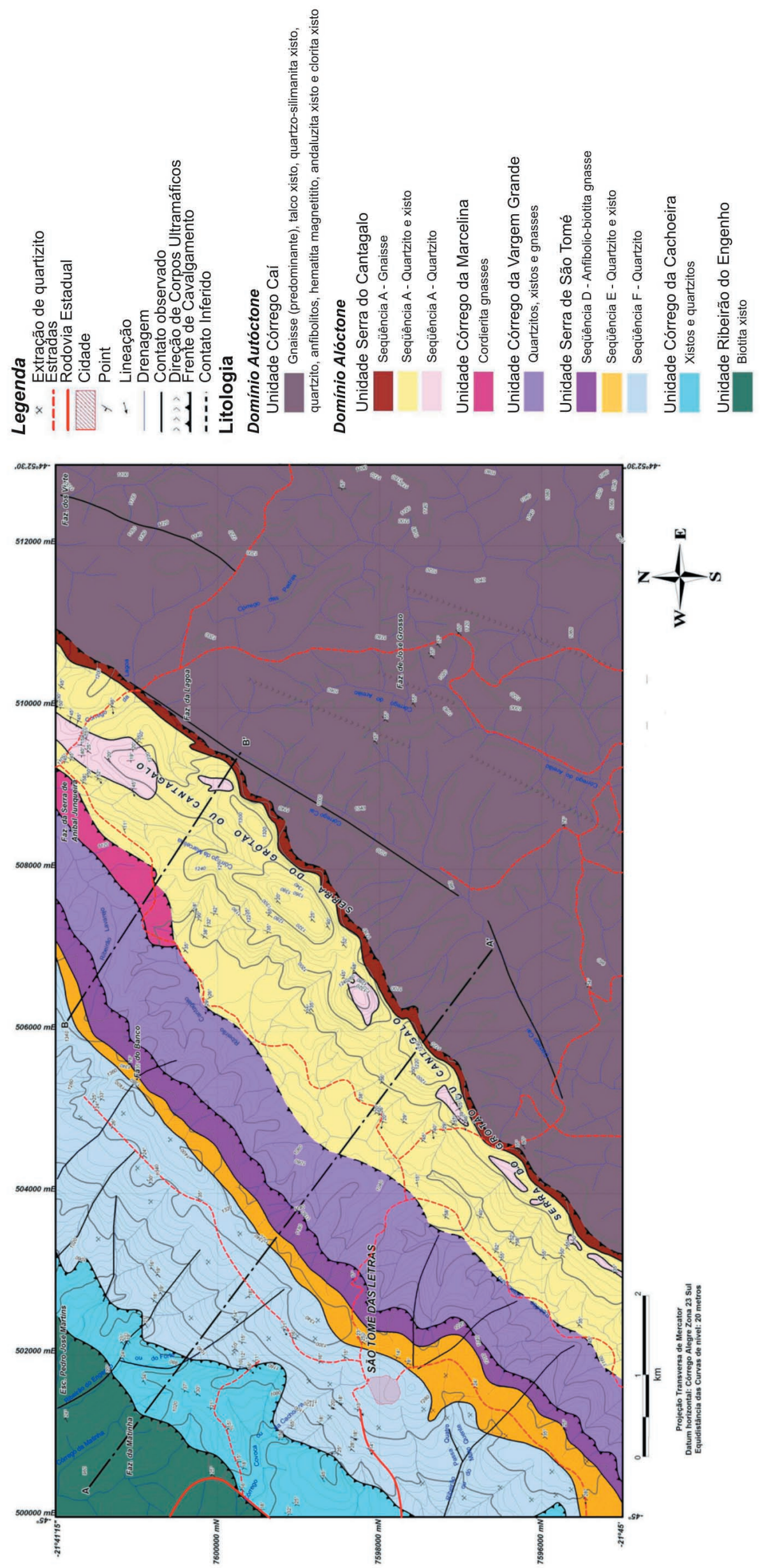

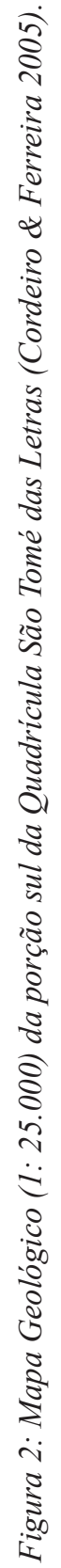


Em todos os gráficos de cintilometria (Figura 7) temse a distância acumulada entre os pontos (em metros) no eixo x e os valores de cintilações por segundo (cps) e altitude (em metros) no eixo y.

Observa-se em todos os radargramas obtidos uma nítida transição, por toda a extensão dos perfis, de solo (região em que a superfície de reflexão é contínua e paralela ao relevo) para saprolito (região do perfil, abaixo da superfície de reflexão do solo sem estruturas capazes de promoverem a reflexão da onda emitida) e a seguir rocha sã.

Característica também comum em todos os perfis realizados é a presença de refletores contínuos, com mergulho para os quadrantes $\mathrm{W}$, atribuído ao padrão estrutural regional encontrado para todos os litotipos mapeados na região. Nos perfis realizados na escarpa leste da Serra do Cantagalo (Figura 4A e 4B) esse padrão pode ser verificado nos refletores 1 ; no Vale 1 (Figura 5C) e Vale 3 (Figura 6E) a todos os refletores identificados nos radargramas e no Vale 2 aos refletores 2, 3, 4 e 6 (Figura 5D).

Uma segunda superfície refletora comum nos perfis realizados, normalmente com inclinação maior do que a topografia do terreno e oblíqua ao primeiro refletor descrito, é correlacionada à família de fraturas perpendiculares à direção das serras de São Tomé e Cantagalo, a qual pode ser confirmada pelos refletores 3 nas figuras 4Ae 4B.

A existência de contatos litológicos nos perfis realizados pode ser inferida a partir de rupturas de relevo associadas ou não à mudanças/atenuações no padrão de reflexão. Na Região 1 das figuras 4A e 4B a atenuação do Refletor 1, atribuído aos planos de foliação em quartzitos e moscovita xistos, é associada à presença (localmente aflorante) de gnaisse, que por não possuir planos de foliação bem desenvolvidos como aqueles encontrados nos quartzitos e xistos, não possui superfícies refletoras tão evidentes. Ainda no perfil 4A, obtido na escarpa leste Serra do Cantagalo, uma ruptura de relevo, próxima à distância de $120 \mathrm{~m}$, associada à nova modificação do padrão de refletores (Região 2) permitem deduzir um novo contato, desta vez entre litologias similares, visto que a mudança de padrão é sutil.

De maneira semelhante, a Região 1 na figura 5C é interpretada como um contato litológico entre quartzosillimanita xisto e talco xisto, visto que além de uma sutil ruptura de relevo, os refletores da Região 2, caracterizados por uma superfície refletora superficial, com inclinação suave e levemente ondulada, tornam-se a partir da distância de $35 \mathrm{~m}$, mais inclinados, porém ainda ondulados, gerando ainda outras reflexões. Já o refletor 5 na figura $5 \mathrm{D}$ é correlacionado à um contato entre talco xisto e gnaisse.

No perfil Vale 4 (Figura 6F), todos os refletores identificados no radargrama podem ser associados à contatos litológicos já que estes puderam ser verificados em campo, desta forma, o Refletor 1 é relacionado ao contato entre gnaisse e talco xisto, o qual ocorre próximo à distância de $10 \mathrm{~m}$, o Refletor 2 é associado à contato entre talco xisto e quartzo-sillimanita xisto na distância de $30 \mathrm{~m}$ e o Refletor 3 é interpretado como contato entre quartzo-sillimanita xisto e outro nível gnáissico.

Alguns refletores têm sua interpretação limitada por se encontrarem em profundidades maiores e por possuírem pouca amplitude e continuidade lateral, contudo, o Refletor 5 da figura 4B pode estar relacionado à presença de falha normal no pacote de gnaisse.

O Refletor 1 da figura 5D, formado por uma superfície refletora com inclinação para o quadrante oposto ao padrão estrutural regional é associado à reflexão da onda EM numa arvore próxima ao perfil.

A inclinação, forma e freqüência com que algumas vezes as superfícies de reflexão são truncadas, peculiares ao perfil Vale 3 (Figura 6E), podem estar relacionadas à interferência sofrida pela onda emitida ao incidir sobre planos de foliação e planos de fraturas discordantes dos primeiros, ou famílias de fraturas com direções diferentes.

A análise da cintilometria obtida no perfil ao longo da escarpa E da Serra do Cantagalo (Figura 7A) mostra, em termos de topografia, a existência de três domínios geomorfológicos, determinados por variação no ângulo de inclinação do perfil topográfico e por variações cintilométricas cujos picos são 900 e 1.100 cps com valores médios de $733 \mathrm{cps}$, aproximadamente coincidentes com os domínios geomorfológicos.

O primeiro domínio geomorfológico é marcado pelos valores de 1.100 a 700cps em uma distância de cerca de $25 \mathrm{~m}$. A primeira medida realizada, caracterizada por valor de cintilação mais alto $(1.100 \mathrm{cps}$ - Pico 1), é atribuída ao nível de moscovita xisto contendo intercalações de quartzito.

Uma relativa homogeneidade de valores de cintilações (próximos de 700cps) distingue o segundo domínio geomorfológico, iniciado por um pico de $1.050 \mathrm{cps}$ (Pico 2) e com aproximadamente $75 \mathrm{~m}$ de extensão. O Pico 2 é interpretado como um contato geológico - observado em campo - entre pacote de moscovita xisto com intercalações de quartzito e gnaisse fitado.

O terceiro domínio geomorfológico é assinalado por valores de cintilações entre 700 e $800 \mathrm{cps}$, também marcado por picos de cintilações (Pico 3, por exemplo), associado à existência de um novo contato geológico, desta vez entre dois níveis de gnaisse.

Como esperado, os picos 2 e 3 , bem assinalados no gráfico de cintilometria, encontram correspondência com as regiões 1 e 2 , respectivamente, do radargrama equivalente (Figura 4A).

Os perfis cintilométricos realizados ao longo dos vales 1 e 2 são caracterizados por médias de $367 \mathrm{cps}$ e $731 \mathrm{cps}$ e desvios padrão de $78 \mathrm{cps}$ e $70 \mathrm{cps}$, respectivamente (Figuras $7 \mathrm{~B}$ e $7 \mathrm{C}$ ).

Diferentemente do gráfico obtido para a Serra do Cantagalo (Figura 7A), não há grandes picos 


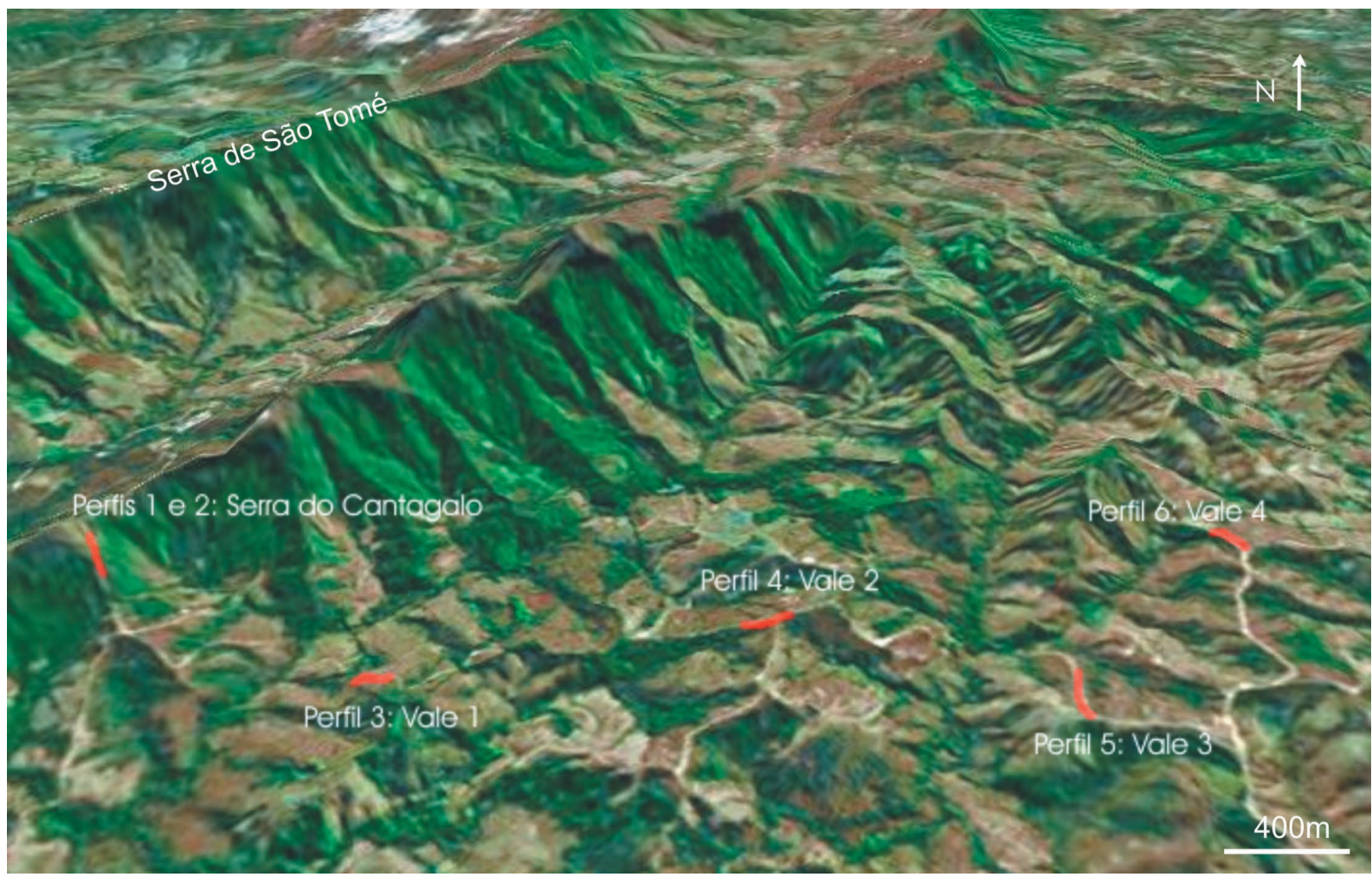

Figura 3: Localização, em imagem de satélite, dos perfis de geofisica (traços vermelhos, fora de escala para representar a extensão do perfil) GPR e cintilometria realizados. Fonte: http://earth.google.com,

último acesso em 10/11/2005.

nem variação expressiva nos valores de cintilação medidos.

Dentre os vários pequenos picos e depressões identificados (por exemplo, nas distâncias de $16 \mathrm{~m}, 24 \mathrm{~m}$, 56m na Figura 7B), apenas a depressão nos valores de cintilações por segundo na extensão de $16 \mathrm{~m}$, apresenta correlação com o radargrama equivalente (Figura 5C) correspondendo à Região 1, interpretada como zona de contato entre o quartzo-sillimanita xisto e talco xisto. Assim como o contato entre talco xisto e gnaisse, identificado como Refletor 5 no perfil de GPR (Figura 5D, distância de cerca de $90 \mathrm{~m}$ ) aparece de maneira bastante sutil no gráfico de cintilações (Figura 7C), correspondendo a um pico de $880 \mathrm{cps}$.

Ainda que outros picos possuam um refletor na mesma extensão do perfil, estes valores anômalos de cintilações são atribuídos à um possível enriquecimento local em elementos radioativos, seja a partir de alterações intempéricas ou conseqüência de transporte de material (solo transportado) de montante para jusante (Figura 7B, curva topográfica), ou, ainda, resultante de variações na espessura da camada de solo.

Já o gráfico cintilométrico obtido no perfil Vale 3 (Figura 7D) é caracterizado por média elevada de valores de cintilações, correspondendo a $1.686 \mathrm{cps}$, com desvio padrão de 140 (dobro do encontrado para os perfis anteriores).

Embora o máximo de cintilações esteja em $1.900 \mathrm{cps}$ e o mínimo em $1.360 \mathrm{cps}$, correspondendo às medidas mais altas obtidas, estes valores não possuem correspondência topográfica. Os altos valores para esse perfil podem ser atribuídos aos minerais que compõem o gnaisse, os quais permitem a substituição de elementos como $\mathrm{K}$ por $\mathrm{Rb}$ e Sr, todos os três radioativos. Os valores de cintilações significativamente (e abruptamente) mais baixos do que a média (distâncias de $15 \mathrm{~m}, 34 \mathrm{~m}, 57 \mathrm{~m}$ e $73 \mathrm{~m}$, por exemplo) são atribuídos à provável existência de veios de quartzo, relativamente comuns na região circunvizinha à esse perfil.

Por sua vez, o gráfico cintilométrico correspondente ao perfil Vale 4 (Figura 7E) possui valores médios de cintilações de $559 \mathrm{cps}$, com desvio padrão de $82 \mathrm{e}$, apesar de possuir valores semelhantes àqueles medidos nos perfis Vale 1 e Vale 2, aqui é possível caracterizar duas regiões de valores crescentes de cintilações (regiões 1 e 2) e uma de valores decrescentes (Depressão).

O pico de $750 \mathrm{cps}$ medido no início do perfil pode ser atribuído à uma (pontualmente) menor espessura da camada de solo. A partir desse pico os valores oscilam entre 500 e $600 \mathrm{cps}$, caracterizando a Região 1 da Figura 7E.

$\mathrm{Na}$ distância a partir de $24 \mathrm{~m}$, os valores medidos são decrescentes (variação de 410 a $500 \mathrm{cps}$ ), porém chegam a alcançar picos de 530 e $550 \mathrm{cps}$, os quais são, também associados à uma menor espessura, local, do nível de solo. Esta região com extensão aproximada de $30 \mathrm{~m}$ forma a Depressão, assinalada na Figura 7E.

Valores de cintilações crescentes representam a Região 2 da Figura 7E, com medidas variando de 550 a $650 \mathrm{cps}$.

Tanto as regiões caracterizadas por valores mais 

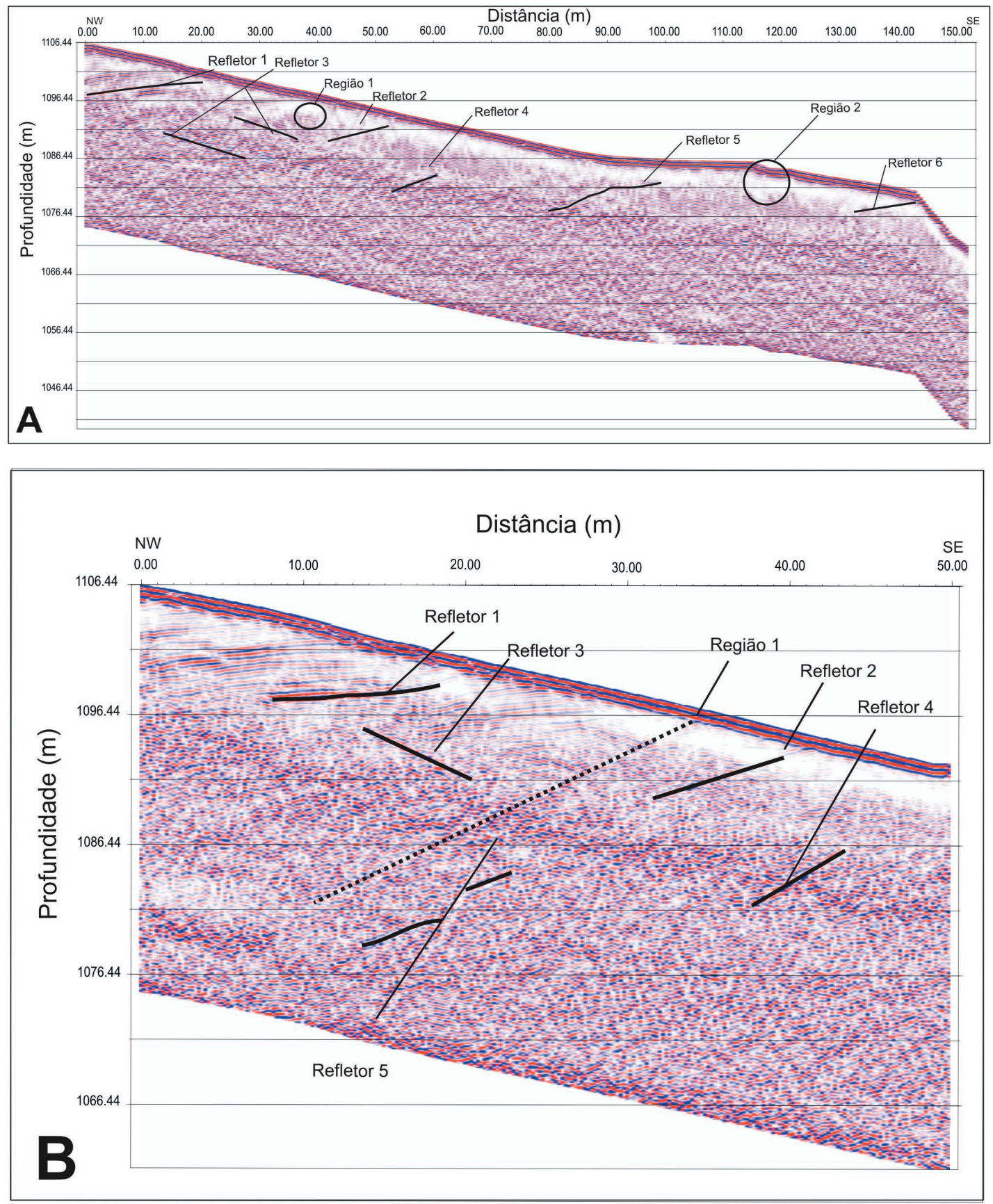

A - Radargrama obtido na escarpa leste da Serra do Cantagalo, antena de $50 \mathrm{MHz}$.

A - Radargrama obtido na escarpa leste da Serra do Cantagalo, antena de $100 \mathrm{MHz}$.

Figura 4: Radargramas obtidos (A) na escarpa leste da Serra do Cantagalo, antena de 50MHz e (B) escarpa leste da Serra do Cantagalo, antena de $100 \mathrm{MHz}$.

altos de cintilações, quanto a região representada por valores baixos, são correlacionáveis aos refletores 1, 2 e 3 identificadas no radargrama da Figura 6F, correspondendo aos contatos entre (1) gnaisse e talco xisto (Refletor 1/Região 1), (2) talco xisto e quartzosillimanita xisto (Refletor 2/Depressão) e (3) quartzosillimanita xisto e gnaisse (Refletor 3/Região 2).

\section{CONCLUSÕES}

Os métodos geofísicos podem ser de grande valia como auxílio aos mapeamentos geológicos, principalmente na ausência de afloramentos, como é o caso da porção a leste da Serra do Cantagalo na Quadrícula São Tomé das Letras, sul de Minas Gerais. 

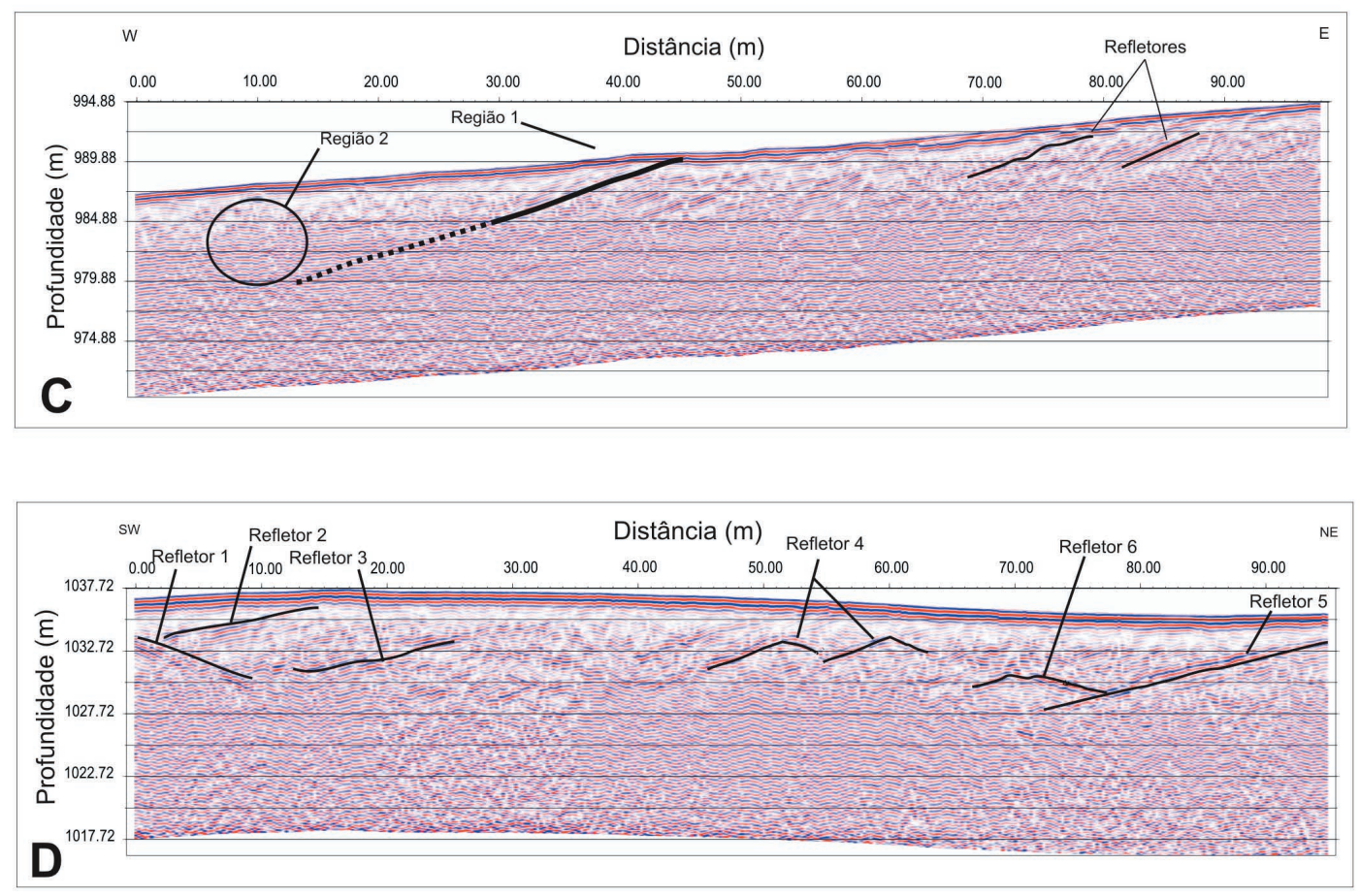

\section{C - Radargrama obtido no Vale 1, antena de $100 \mathrm{MHz}$. \\ D- Radargrama obtido no Vale 2, antena de $100 \mathrm{MHz}$.}

Figura 5: Radargramas obtidos (C) Vale 1, antena de 100MHz e (D) Vale 2, antena de 100MHz.
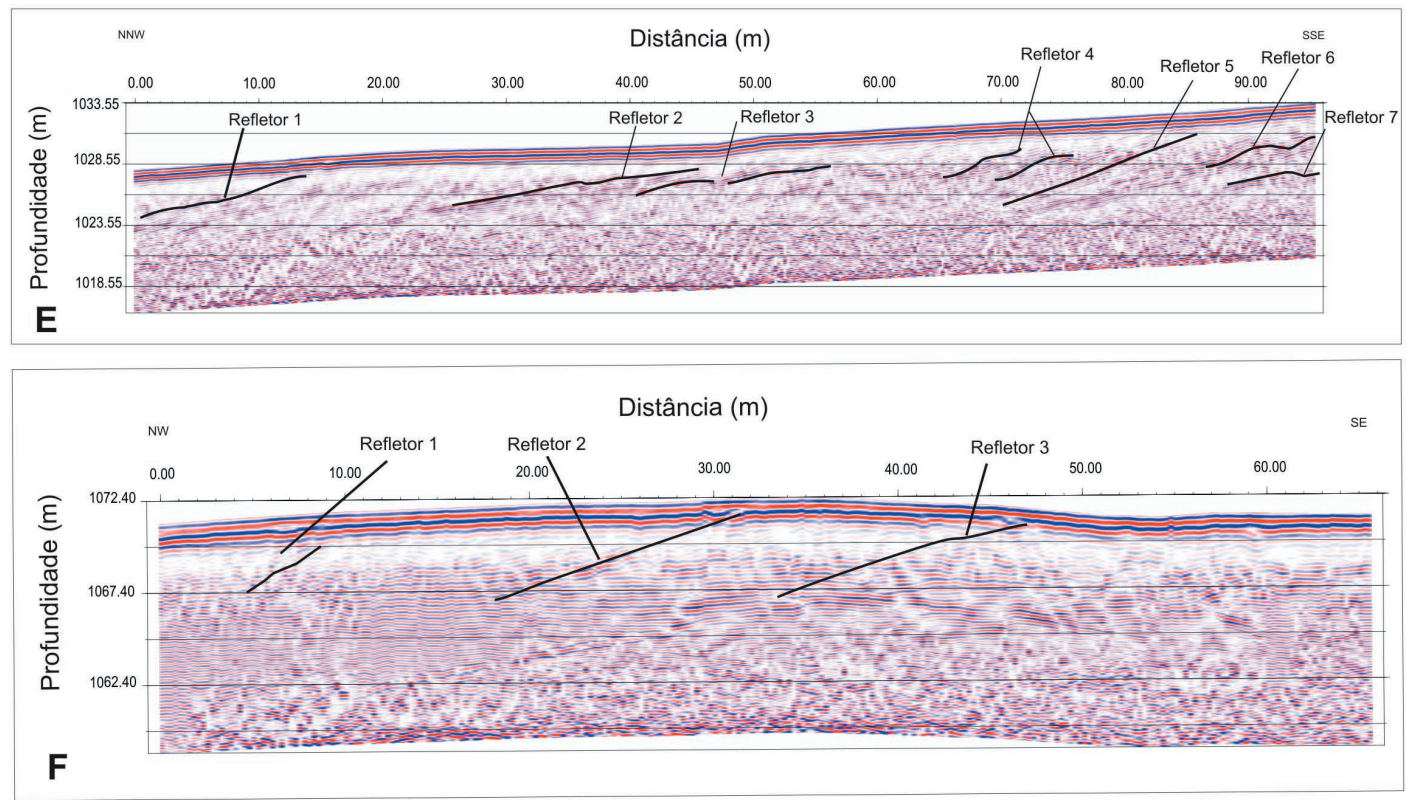
E - Radargrama obtido no Vale 3, antena de 100MHz.
F - Radargrama obtido no Vale 4, antena de $100 \mathrm{MHz}$.

Figura 6: Radargramas obtidos (E) Vale 3, antena de 100MHz e (F) Vale 4, antena de 100MHz. 
O método de Georadar apresentou bons resultados na identificação de mudanças de padrões de reflexões, caracterizando possíveis contatos litológicos (corroborados por variações cintilométricas), planos de foliação ou famílias de fraturas, evidenciando sua ampla aplicação em depósitos supergênicos, marcando claramente contatos entre solo, saprolito e rocha sã.

Os contatos litológicos podem ser inferidos com relativa confiabilidade, tanto nos radargramas quanto nos gráficos de cintilometria correspondentes, sendo na maior parte das vezes associados às modificações nos padrões de reflexão e/ou rupturas de relevo - nos radargramas, e por variações bruscas nos valores de cintilações - nos gráficos de cintilometria.

Os planos de foliação apresentam-se, comumente, como um padrão de reflexão contínuo, com inclinação para os quadrantes $\mathrm{W}$, enquanto um segundo padrão de reflexão, normalmente com inclinação maior do que a topografia do terreno e oblíquo aos refletores associados aos planos de foliação, é correlacionado à família de fraturas perpendiculares à direção das serras de São Tomé e Cantagalo.

As dificuldades quanto à aplicação dessas técnicas geofísicas surgem, principalmente, quando da aplicação do Georadar em material com características elétricas condutoras (o qual gera dispersão da onda EM) e nas proximidades de árvores, gerando ruídos nos radargramas.

\section{AGRADECIMENTOS}

Os autores desejam agradecer ao Dep. Geologia - IGC/UFMG, ao Geól. Carlos von Sperling (INSTRUTEC), às empresas mineradoras do município de São Tomé das Letras pelo auxílio financeiro e ao corpo consultivo da Geonomos pelas valiosas sugestões e comentários sobre o artigo.
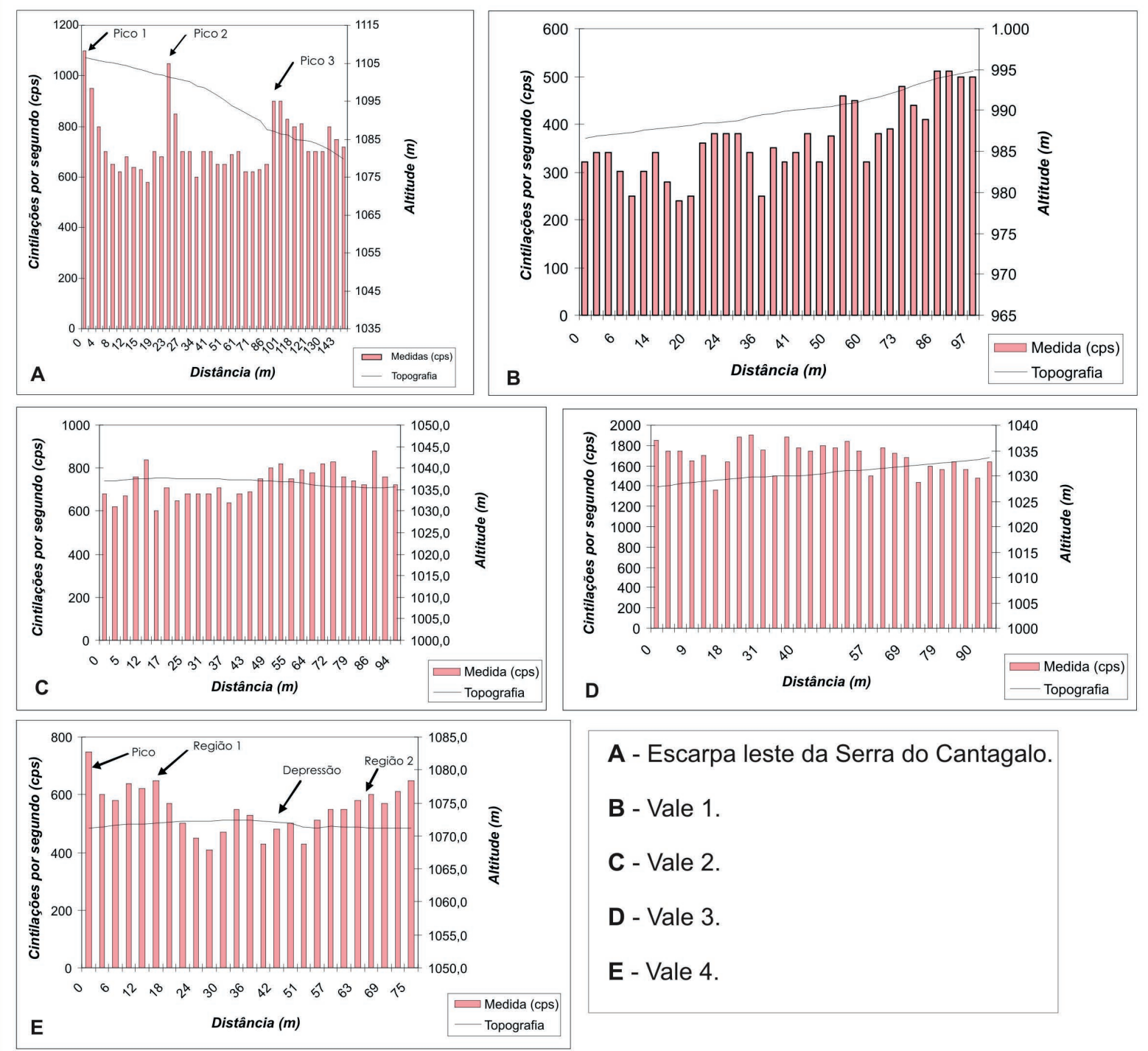

Figura 7: Gráficos de cintilações por segundo x distância x elevação obtidos (A) na escarpa leste da Serra do Cantagalo; (B) Vale 1; (C) Vale 2; (D) Vale 3 e (E) Vale 4 


\section{REFERÊNCIAS BIBLIOGRÁFICA}

Aranha P.R.A. 2003. Estudo das coberturas superficiais e sua dinâmica na região de Gouveia, Serra do Espinhaço, MG: utilizando o Radar de Penetração no Solo (GPR). Tese de Doutorado, UFOP, Ouro Preto, 305p.

Aranha P.R.A \& Horn A. H. 2000.Investigações estruturais de um dique máfico caulinizado na Serra do Espinhaço Meridional, utilizando o GPR. Geonomos 8 (1): 69-76.

Aranha p.R.A., Augustin c.H.R.R., Lucio p.S., Neves f.A.P.S. 1998. Estudo das coberturas superficiais na região de Gouveia - MG, com o uso de GPR (Ground Penetrating Radar). In: XL Congresso Brasileiro de Geologia, Belo Horizonte, Seção Pôster. CD.

C J.S. \& Ferreira A.F. 2005. Mapeamento geológico da porção sul da Quadrícula São Tomé das Letras. Trabalho de Graduação IGC/UFMG, Inédito, $124 \mathrm{p}$
Horn A.H., Aranha P.R.A., Neves S.C., Viana Fo , L., Ádamo R.G. 1998. Novos dados sobre a ocorrência de fosfatos e silicatos de Al-Fe na Serra do Espinhaço Meridional - Perfis nas regiões da Serra da Miúda e Fazenda Formação - Diamantina, Minas Gerais. In: XL Congresso Brasileiro de Geologia, Seção Pôster. $\mathrm{CD}$, Belo Horizonte.

Neves F.A.P.S., Aranha P.R.A., Lucio P.S., 1997. Estudos de voçorocas usando GPR. In: Simpósio Regional de Geologia (SBG), Penedo. Resumos. 120p.

Trouw R.A.J., Ribeiro A., Paciullo F.V.P. 1980. Evolução metamórfica e estrutural de uma área a SE de Lavras, MG. In: Anais do XXXI Cong. Bras. Geol., Santa Catarina, vol. 5, p. 2773-2784.

Trouw R.a.j., Ribeiro A., Paciullo F.V.P. 1983. Geologia estrutural dos grupos São João Del Rei, Carrancas e Andrelândia, sul de Minas Gerais. An. Acad. Bras. Ciên., 55 (1): 71-85.

Trouw R.A.J., Ribeiro A., Paciullo F.V.P. 2003. Geologia da Folha Caxambu. In: CODEMIG, Projeto Sul de Minas- Etapa I. CD 2003 . 